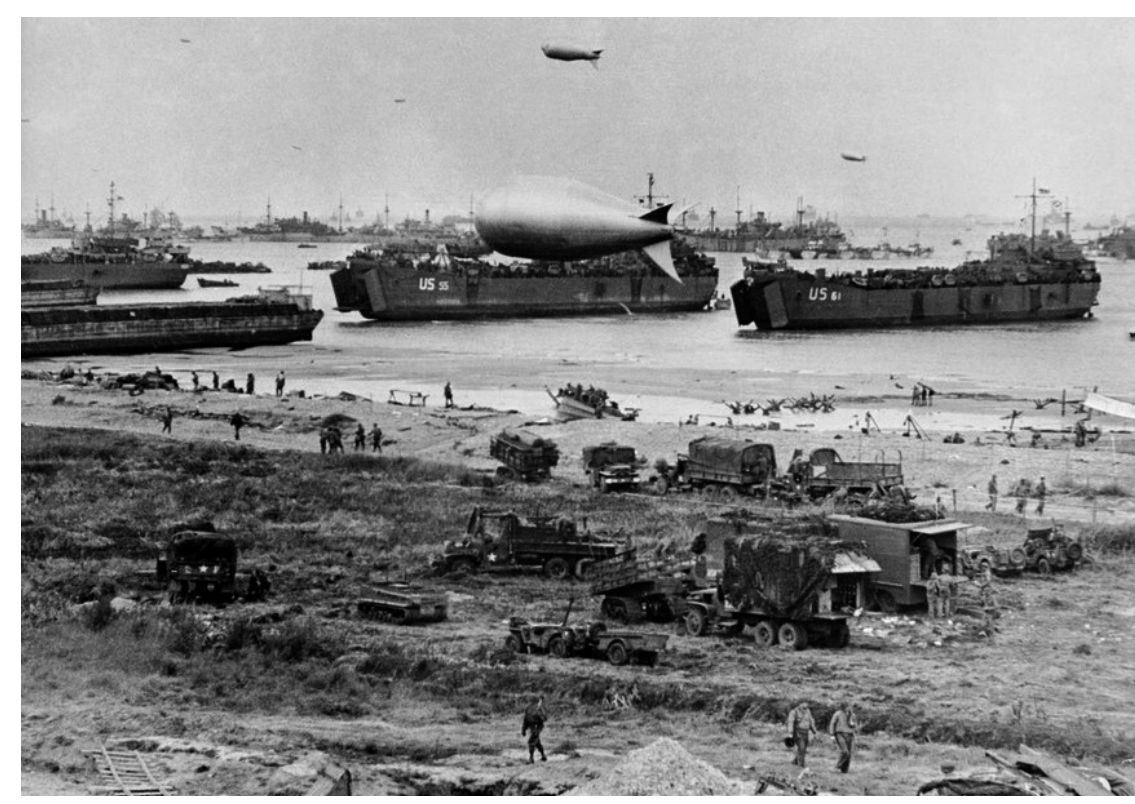

FIG. 1. Desorden aparente en el Día D de la invasión de Normandía 6 de junio de 1944.
Fuente: https://www.iwm. org.uk/history/the-10-things-you-need-to-know-about-d-day

\title{
Información y forma en la ciudad contemporánea
}

\author{
Evelyn Alonso Rohner, José Antonio Sosa
}

Recibido 2019.04.29 ::: Aceptado 2019.04.30

DOI: 10.5821/palimpsesto.19.8259

ABSTRACT

La estructura de la ciudad debe mucho al modo en que se produce la información sobre la misma. La más elemental - que es entender sus jerarquías, recorridos, funcionamiento, así como nuestra posición en su interior - ha requerido históricamente de un soporte físico urbano capaz de transmitir esa información (trazas, geometrías, ejes). Pero, si la necesidad de información determinó históricamente la forma urbana y su entendimiento ¿qué ocurre cuando ambos factores se desvinculan, como sucede hoy en día? ¿Qué ocurre cuando la información no precisa del soporte físico urbano?

Se trata de entender la nueva logica difusa de la ciudad contemporanea. Se realiza para ello un análisis de la relación entre forma y sistema de información, abierto y de manera inter-disciplinar. Investigando para ello tres sectores en los que la forma física reacciona e interactúa frente al sistema imperante de información de cada momento de manera semejante: la táctica bélica, la logística (y el almacenaje "caótico" del presente), y por supuesto, la propia evolución de la forma urbana.

La realidad que empieza a ser constatable es que la ciudad (y sus usos y recorridos) se reorganiza bajo

nuevos parámetros que no dependen directamente de la

forma urbana. La toma de decisiones individual,

información facilta que se produzcan cambios de

localizaciones de los usos más diversos. Estos cam

aranzan una ciuded de orden aun más disperso y

multicapa.

PALABRAS CLAVE: urbanismo; información; big data; orden caótico; arquitectura.

Persona de contacto: jasds@joseantoniososa.eu. Departamento de Proyectos Arquitectónicas de la Escuela de Arquitectura de la Universidad de Las Palmas de Gran Canaria.

\section{Introducción}

La estructura de la ciudad debe mucho al modo en que se produce la información en cada momento. La más elemental, que es entender la ciudad y sus partes, sus jerarquías, los recorridos posibles, su funcionamiento, sus novedades, así como nuestra posición en su interior, se apoyó históricamente en el soporte formal urbano para transmitir la información. Este se basaba en las trazas geométricas, IOs ejes, aluras $y$

desarrolladas en geometrías sucesivas, pretendían básicamente mantener la "formación", ya que de ella dependía la "información" y, en consecuencia, la batalla.

Pocos años más tarde, las imágenes del desembarco de Normandía muestran lo que parece ser el caos formal de la guerra "moderna". La estructura geométrica se sustituye ahora por una disposición de apariencia desordenada y compleja. Para hacer posible ese desorden visual, ha debido encontrarse un sistema de información alternativo, capaz de sustituir a la geometría. El artilugio que permitió la nueva estructura formal fue la radio, al hacer posible la transmisión de órdenes "invisibles"; haciendo por lo tanto innecesario, el sostenimiento del orden geométrico ${ }^{1}$

Hoy en día, la guerra es la de la información digital, que se desliga del plano geográfico o físico; que ocurre en cualquier lugar y cualquier momento. Hoy la guerra es ganada o perdida en el campo de la información y el control de los datos. Paul Virilio, en entrevista con Philippe Petit, ya adelantaba en 2004 esta situación en el "Cibermundo, la Política de lo Peor". Y la cosa, efectivamente ha ido a peor. En este nuevo escenario, la guerra trae nuevas implicaciones que afectan a lo físico, pero sin tocarlo.

¿Qué sentido puede tener la frontera cuando la información lo atraviesa todo? El orden de la nueva guerra es el orden global de la información, que vive desligada del plano geográfico o físico; es decir, que sucede en cualquier lugar y en cualquier momento ${ }^{2}$.

Tras este repaso rápido a la evolución de la información y la forma en la guerra, volvemos al terreno de lo urbano. La ciudad obedece a una complejidad muy superior a la de la formación militar, en ella se solapan factores, muchas veces contradictorios o antagónicos entre sí, y de índole muy diversa (económicos, políticos, estratégicos, religiosos...), pero capaces de convivir simultáneamente. No obstante, es posible realizar una breve comparación entre la evolución de la ciudad y la guerra desde parámetros semejantes.

La organización de las primeras concentraciones urbanas, con su posterior concentración de poder y su necesidad de representación, fue ganando complejidad funcional, haciendo necesarias disposiciones expresas para hacer más visible su estructura, dotándolas de un orden explícito y entendible por todos. Organizar los recorridos facilita el entendimiento de la ciudad: ordenar los usos facilita las transacciones; dar más altura a unos edificios señala su jerarquía... En este contexto, la geometría ayuda a entender los recorridos y la jerarquía posicional. información más asequibles que nunca, se tien opción de conocer esa localización de usos, recorridos, o la propia estructura urbana, sin necesidad de "entender" físicamente la ciudad. Los nuevos sistemas informativos son globales y ubicuos, cubren la ciudad entera, aunque de forma fragmentada; y se encuentran asequibles en la palma de nuestra mano.

Y si la necesidad de información determinó históricamente la forma urbana, ¿qué ocurre en un sistema en que la información circula por las redes? Es decir, ¿qué ocurre cuando ambos factores (forma e información) se desvinculan? La consecuencia natural debería ser que la ciudad (con sus usos y recorridos) se reorganiza bajo nuevos parámetros, que no dependen ni precisan directamente de su estructura física.

\section{El papel estructurante de la} información

Para tratar de explicar la capacidad que tiene la información para estructurar la ciudad, puede empezarse por analizar un sector donde este fenómeno es más evidente, como es el militar, y allí comprobar como la geometría de las formaciones militares - como la de las tramas urbanas - lejos de ser un asunto formal como puede parecer a primera vista, obedece a la necesidad de un sistema informativo y posicional.

La disposición geométrica en "formación" de las guerras pre-napoleónicas, responde a razones básicamente organizativas; su función no era alardear de entrenamiento, tanto como comunicar, a cada miembro del batallón, cuál debía ser su posición en cada momento. Su estricta geometría era producto, principalmente, de la necesidad de información. Las formaciones geométricas militares se perpetuaron, con ligeros cambios, desde Roma hasta principios del siglo XX. En los manuales de táctica militar de esta época, aunque expresados mediante una abstracción próxima a la de una partitura contemporánea, se describen las disposiciones más adecuadas para cada movimiento de ataque o de repliegue. Estas instrucciones tácticas,
Esa complejidad creció sin parar hasta hoy. En el proceso de su evolución, unido al auge de los viajes, jugó un papel importante para entender la ciudad cada vez más compleja el mapa. Pero el mapa, y esto es importante, trascendía su papel informativo, convirtiéndose de manera involuntaria en un elemento ordenador. A partir de su uso extensivo (que llegó casi hasta el presente) se produjo un fenómeno de retroalimentación: la información esquematizada y simplificada, al fijar básicamente los recorridos y lugares más destacados, reorientó el desarrollo y crecimiento de la ciudad. El mapa no sólo informó también reordenó y modificó la ciudad. A modo de ejemplo: la mayor afluencia de visitantes a las áreas más destacadas en el mapa, alteró el comercio, especialmente a lo largo de las rutas seguidas, produciendo un efecto dinamizador. Este tipo de interacción mutua, por la que el elemento informante (de una realidad existente) se convierte en modificador de esa misma realidad, constituye el inicio de algo que irá acentuándose en etapas posteriores: la capacidad del sistema de información para reestructurar la forma.

La explosión demográfica en las metrópolis en las últimas décadas del siglo XX incrementa exponencialmente su complejidad. Perdida (por excesivamente compleja) la codificación formal de la ciudad, se recurre a un nuevo sistema de información a través del GPS. Este, al principio, funciona como inocente sustito del mapa, pero luego, como ocurrió con aquel pero a mayor escala, se convierte en un potente reconfigurador de la propia ciudad.

Hoy no es necesaria una geometría específica y preestablecida, ni tampoco rutas conocidas para llegar hasta el hospital o la farmacia de guardia. Basta dejarse guiar por un navegador. $Y$ ya empieza a ser bastante frecuente que el camino sugerido por ese navegador ni siquiera coincida con el que se considera "de siempre” como el más corto. Porque, a diferencia de nuestra información mental (o de la de un mapa), la del 


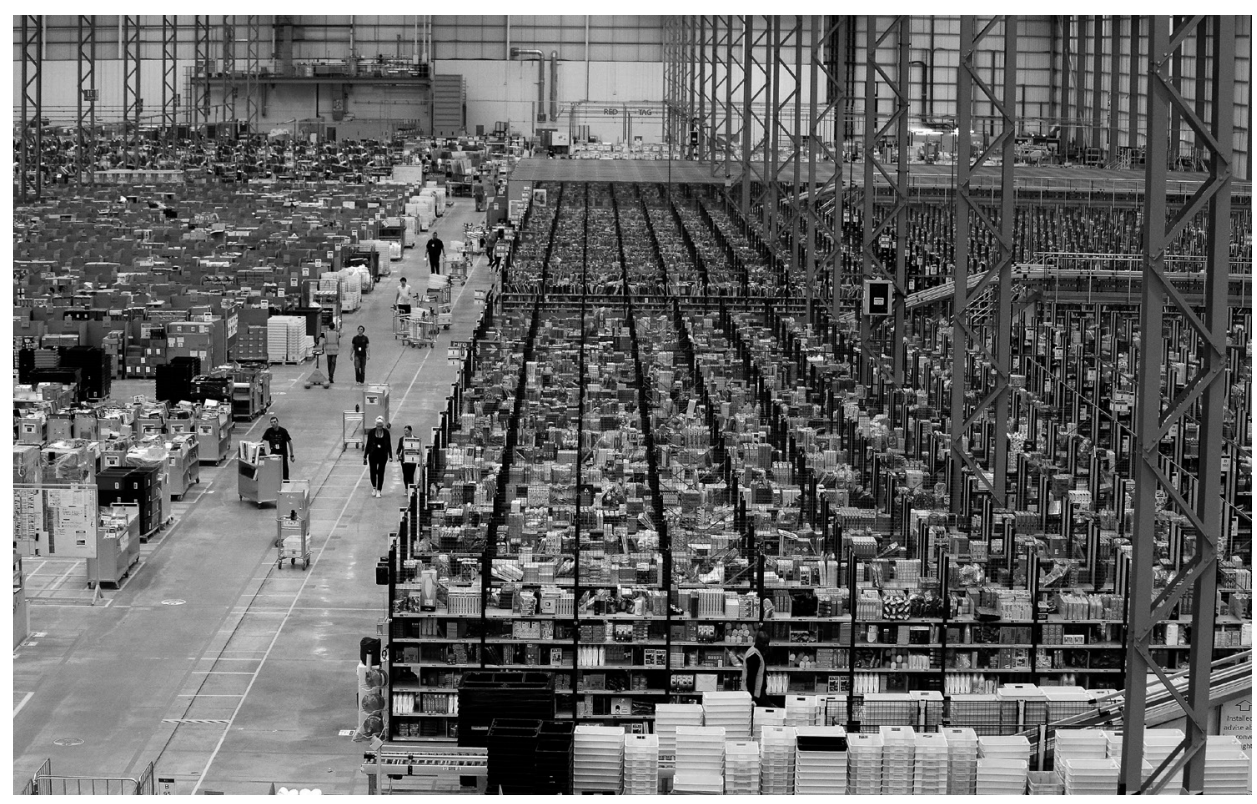

FlG. 2. "Almacenaje caótico" de los objetos pendientes de envío en un almacén de Amazon.
Fuente: https://www.racked.com/2018/3/30/17180344/amazon-congress-walmart-ceo
Este modo de ordenar utiliza también la verticalidad; para ser localizable, no se precisa de un nivel o altura concreta. El objeto puede almacenarse en lo más alto. También en la ciudad comienza a ocurrir lo mismo con la altura. Un sitio interesante ya no tiene que estar a ras de suelo para ser visitado. Otra característica del orden de Amazon es permitir la discontinuidad en cualquier dimensión. En él se producen espacios vacíos intersticiales cambiantes, que se van rellenando con apariencia aleatoria. El orden de Amazon favorece de ese modo la entropía. De hecho, la habilita. La entropía no deja de ser una medida del desorden. La entropía aplicada a Amazon, o a la ciudad, significa la desaparición de las estructuras visibles del orden, que pasan a ser innecesarias o contraproducentes. No es que no existan, sino que se han vuelto más finas y más invisibles. De hecho, la entropía y el funcionamiento de estas nuevas estructuras sólo es posible con un aparentemente débil y complejo.

Para visualizarlo se puede uno imaginar las diferencias entre las calles, carreteras y autopistas por las que circulamos, frente a las indeterminadas e invisibles rutas por las que circulan los datos. Esta idea de debilidad y complejidad es tremendamente transcendente a la hora de entender el nuevo planeamiento y así lo recoge Sennett: “...una ciudad abierta trabajaría con sus complejidades, creando, por abierta trabajaria con sus complejidades, creando, por así decirlo, una molécula compleja de experiencia. El complejidad y a la vez crear una ciudad [ville] interactiva y sinérgica, que fuera mayor que la suma de sus partes y dentro de la cual, se produjeran 'bolsas de orden' que pudieran orientar a las personas."

Parte de la cuestión quedaría así delimitada a entender si el rol del urbanista y arquitecto sigue siendo el de visualizar un orden, aunque este sea más complejo, y dónde y de qué modo representar ese orden. dos a lugares, sino a los estratos o capas que se superponen. La ciudad ya no es un collage en planta, sino un sistema multicapa, superpuesto, como un milhojas.

La nueva estructura de la información por capas no se limita a la localización de preferencias. Ese era su cometido inicial pero, como suele pasar, los efectos colaterales suelen ser mayores y más trascendentes. Cada consulta o decisión tomada ahora es registrada masivamente, y produce diversas consecuencias, modificando el modo de uso de la ciudad, y produciendo cambios reales en su estructura social. Cada estrato de información permite de hecho la ubicación de las actividades a que se refiere, según un orden no secuencial o contiguo, sino por oportunidades o acontecimientos.

La ciudad - en el plano absolutamente teórico - no necesita de una forma entendible. Se puede evitar la geometría más allá de la necesidad de la organización de los recorridos (tanto horizontales como verticales). Puede que este orden continúe por costumbre o por nostalgia, o por la gran inercia de las trazas, pero en realidad, ya no se trataría de poder o no poder contar con él, esa no es ya la discusión. Se trata de que a la política - y a la economía - quizás ya no le importe, y probablemente, tampoco le interese, esa organización física predeterminada que le ha servido de base. A menos no aquella que conocemos hasta ahora. En este creciente marco, en el que las acciones individuales modelan de manera emergente la conformación urbana, la disyuntiva entre lo que puede acabar como producto de la economía salvaje o lo humanamente sostenible, girará inevitablemente en torno a la cultura y la ética colectiva e individual.

\section{La capacidad informativa del presente diseña un orden diferente}

Cómo la información altera el orden de las cosas puede verse (no sin cierto asombro) en el sistema logístico de Amazon. Los almacenes de esta multinacional ya no siguen el orden que se le supone a un sistema tradicional de disposición de mercancías. Como ocurre con la ciudad multicapa, sus partes y elementos no se ordenan siguiendo estructuras jerárquicas, ni tipológicas, ni funcionales. Sus almacenes se parecen conceptualmente más a un armazón que al resultado de una idea formal apriorística. Como en la ciudad multicapa, sería totalmente irrelevante cualquier clase de organización basada en lo formal.

El orden de Amazon es el de un caos controlado 4 . Su estudio ayuda a entender cómo la información digital puede modificar el orden físico de las cosas. Su funcionamiento requiere de un gran ordenador, capaz de barajar millones de datos y tomar decisiones para establecer la posición de los objetos basándose en múltiples factores simultáneamente: a dónde va, su tamaño, cuánto tiempo permanecerá en el almacén, dónde hay espacio y cómo logra su selección favorecer la eficacia del almacén, su peso, el modo de transporte, etc. Cada día, su lugar ideal será uno distinto, al lado de un objeto distinto.
1 Basta recordar el esfuerzo de Alain Turing y Joan Clarke
en el intento a contrarreloj por descifrar el código Enigma, para entender la importancia decisiva de la información en

${ }^{2}$ Moisés Naim, El País 31.03.19: "Las invasiones son ahora más baratas, clandestinas y se llevan a cabo con armas cibernéticas y ordenadores

Para más información sobre este aspecto ver "Superposición de Subjetividades. La ciudad

${ }^{4}$ El nombre dado a este tipo de almacenamiento ya es "caotic storage". Bridle, James. New Dark Age. Verso; Londres, 2018

Sennett, Richard. Building and Dwelling, Ethics for the City. 2018 UK; Penguin Random House, pág.9.

BIBLIOGRAFÍA

ALONSO ROHNER, Evelyn y SOSA, José Antonio. Superposición de Subjetividades. La ciudad y lo virtual. En
Rita_07. Madrid, Redfundamentos. 2017 pp.102-109 ISSN 2340-9711.

ÁLVAREZ, Vicente. Estudio gráfico de la Táctica de infantería. Tomo II. Barcelona; Tipolitografía de Luis Tasso, 1899

BRIDLE, James. New Dark Age, Technology and the End of

JENNINGS, Rebecca. Former Walmart CEO, of All People Says Congress Should Break Up Amazon. En: Racked len linea] 30 de marzo de 2018 [consulta: 25 de noviembre de 2018] Disponible en: https.//www.racked.

JOHNSON, Steven. Sistemas emergentes o qué tienen en común hormigas, neuronas, ciudades y software. Madrid Turner Publicaciones, 2003

LYNCH, Kevin. The Image of the City. Cambridge; The MIT

A AlM, Moises. Seis toxinas que debilitan la democracia. En: El País [en línea] 30 de marzo de 2019 [consulta: 30 de marzo de 2019] Disponible en https://elpais.com/elpais/2019/03/30/ opinion/1553965865_689156.htm .

SENNETT, Richard. Building and Dwelling, Ethics for the City. UK; Penguin Random House, 2018.ISBN 9780141022116.

SMITH, Dave. Inside An Amazon Warehouse [Photos]. En: International Business Times [en línea] 29 de noviembre de 2012 [consulta: 10 de diciembre de 2018] Disponible (1) photos-909410.

VIRILIO, Paul. El cibermundo, la politica de lo peor: Entrevista CIRn Philipep Petit. Traducción de Mónica Poole. Madrid;
Cátedra, 2005.

EVELYN ALONSO ROHNER es doctora arquitecta y profesora de Proyectos Arquitectónicos de la Escuela de Arquitectura de la Universidad de las Palmas de Gran Canaria (ULPGC).

JOSÉ ANTONIO SOSA es doctor arquitecto y catedrático del Departamento de Proyectos Arquitectónicos de la Escuela de Arquitectura de la Universidad de las Palmas de Gran Canaria (ULPGC). para entender la importancia dec
resultado final de la contienda. 